\title{
Dissection of interventricular septum by aneurysm of sinus of Valsalva A rare complication diagnosed by echocardiography
}

\author{
WALTER W C CHEN, Y T TAI \\ From the Department of Medicine, University of Hong Kong, Hong Kong
}

SUMMARY A patient with dissection of the interventricular septum by a sinus of Valsalva aneurysm is described. Echocardiographic examination allows the correct diagnosis to be made before cardiac catheterisation.

Dissection of the interventricular septum is a rare complication of sinus of Valsalva aneurysms. ${ }^{1-5}$ This is often diagnosed at necropsy. In this report, we describe a patient with a sinus of Valsalva aneurysm dissecting into the interventricular septum which was diagnosed by two-dimensional echocardiography.

\section{Case report}

A 65 year old man was first admitted into another hospital because of severe precordial gripping pain lasting for two hours. The clinical diagnosis was acute myocardial infarction and this was confirmed by the electrocardiogram which showed acute anterior myocardial infarction. There was a history of exertional angina for several weeks before the admission. The myocardial infarction was complicated by pulmonary oedema which responded to diuretics. While in hospital, aortic regurgitation was also noted. His blood test for VDRL was positive. Soon after improvement, he discharged himself against medical advice and refused further investigations.

He was readmitted in December 1981 because of congestive heart failure. Again he responded to diuretics, and these were continued.

In October 1982, he was admitted into the Grantham Hospital because of pulmonary oedema after omitting drugs for several weeks. Physical examination showed a raised jugular venous pressure. The pulse was 100 a minute, regular, and collapsing. His blood pressure was $170 / 40 \mathrm{mmHg}$. The apex of the heart was at the sixth intercostal space $2 \mathrm{~cm}$ lateral to the mid-clavicular line. The apical impulse showed left ventricular hypertrophy. On auscultation, a grade $3 / 6$ early diastolic blowing murmur was heard along the left sternal border. Bilateral basal crepitations were present on auscultation of the chest. His electro- cardiogram (Fig. 1) showed sinus rhythm. The PR interval was $0.16 \mathrm{~s}$. The $\mathrm{QRS}$ axis was -60 degrees. There was left ventricular hypertrophy with strain. Deep $Q$ waves were present from leads V1 to V4. Chest $x$-ray examination showed cardiomegaly with a cardiothoracic ratio of 0.64 . The lung fields were congested and Kerley's B lines were present. Serological tests for syphilis (VDRL and FTA-ABS) were all positive.

Echocardiographic examination was performed with an Advanced Technology Laboratory mechanical sector scanner, using a 3.0 $\mathrm{MHz}$ transducer. This showed an aneurysm in the interventricular septum. It arose from the right coronary sinus of Valsalva, communicating with the aortic lumen and dissecting into the interventricular septum. It increased in size during diastole and became smaller during systole (Fig. 2). There was also pronounced diastolic fluttering of the anterior mitral leaflet.

Cardiac catheterisation was performed and haemodynamic data showed a raised left ventricular end-diastolic pressure of $24 \mathrm{mmHg}$. The aortic pressure was $150 / 40 \mathrm{mmHg}$ and the pulmonary arterial pressure $60 / 30 \mathrm{mmHg}$. There was no step up in the oxygen saturation in the right heart chambers. Angiographic studies confirmed severe aortic regurgitation. In addition, the right coronary sinus aneurysm together with its dissection into the interventricular septum could be clearly visualised (Fig. 3a). The dye in the interventricular septum stayed for a considerable period of time (Fig. 3b). The coronary arteries were normal and there was: no left to right shunt shown angiographically.

He was treated with diuretics and procaine penicillin 600000 units intramuscularly daily for 14 days, the first three days being covered with steroids. He declined operation and was discharged home on diuretics. 


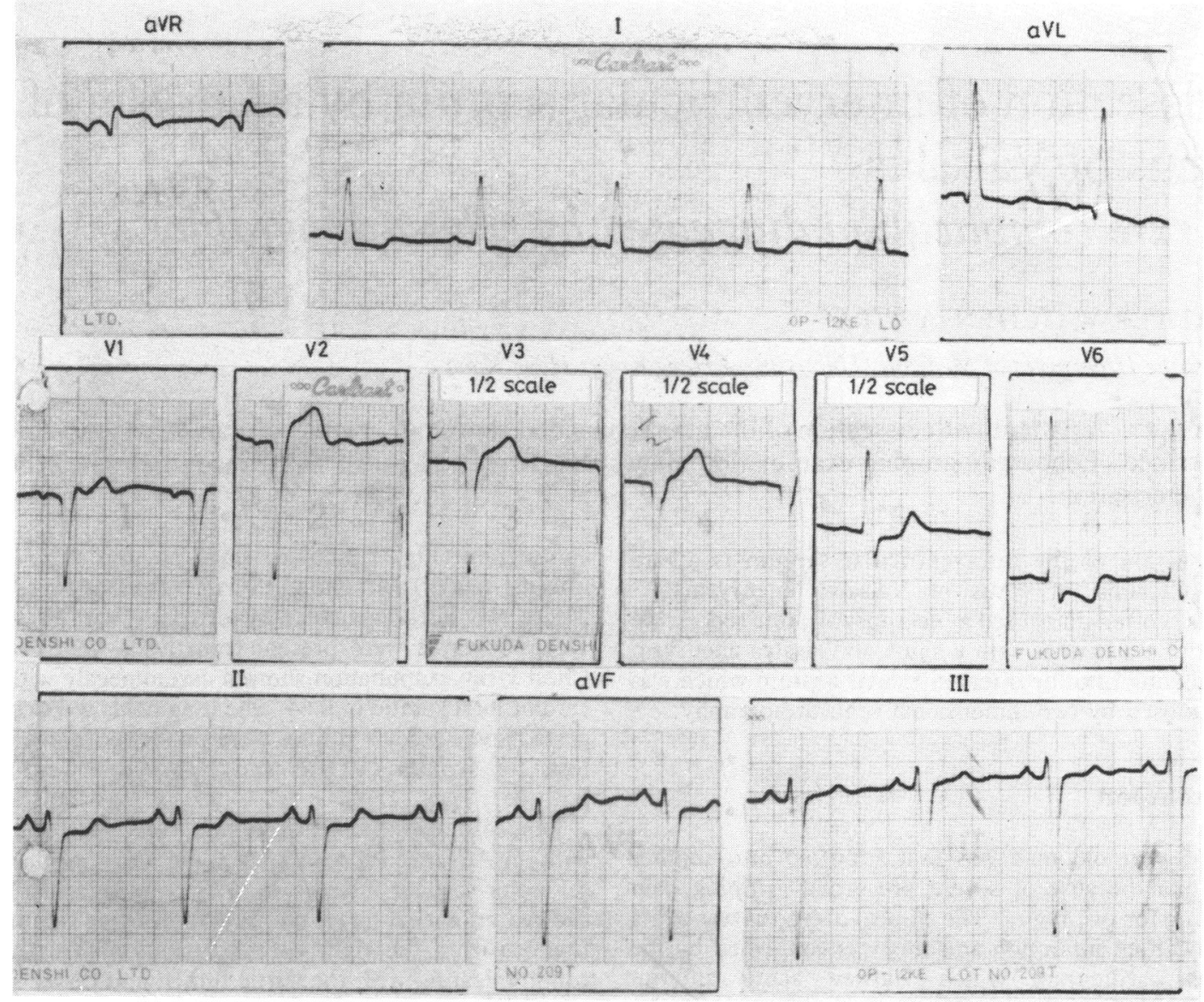

Fig. 112 lead electrocardiogram showing normal $P R$ interval, left axis deviation, and $Q$ waves in leads VI to V4.

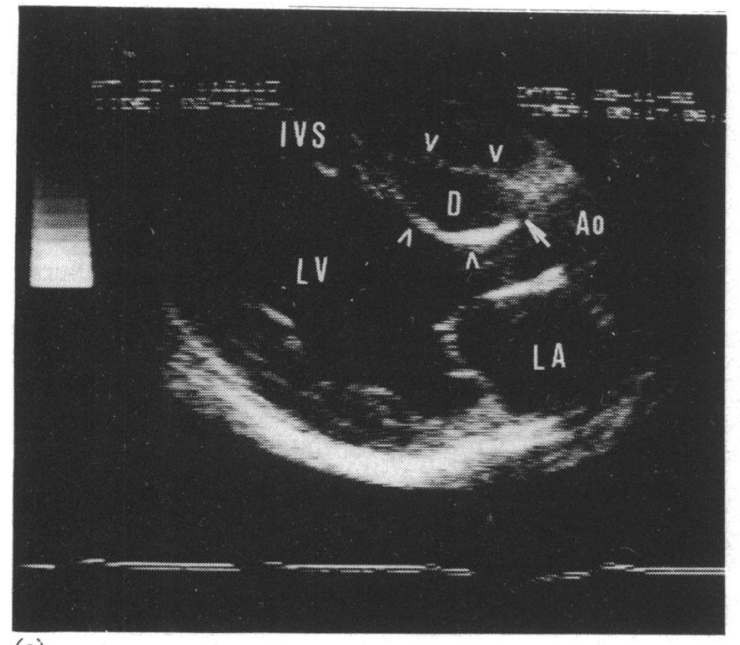

(a)

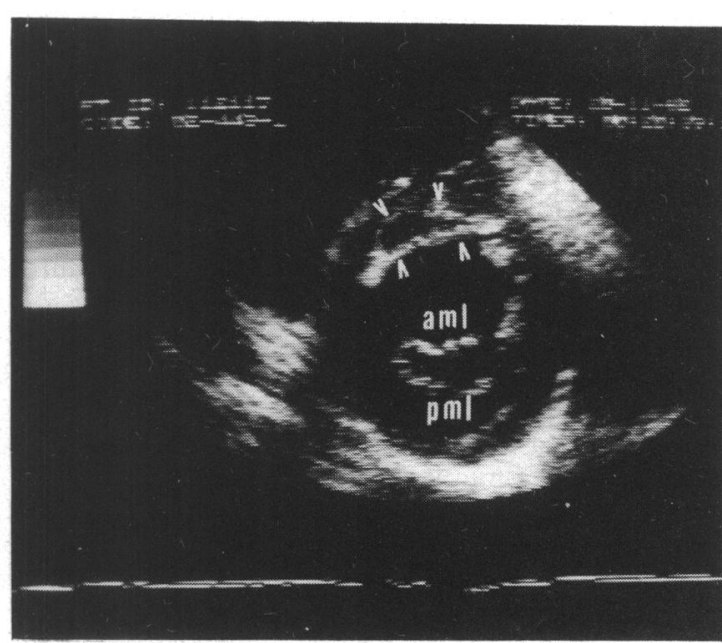

(b)

Fig. 2 Echocardiograms showing the presence of the interventricular septum by an aneurysm of the right coronary sinus of Valsalva. (a) Parasternal long axis view. The dissection (D) is outlined by white arrow heads. It arises from the right coronary sinus of Valsalva and communicates with the aortic lumen as indicated by the white arrow. (b) Parastermal short axis view. The dissection in the interventricular septum is indicated by white arrow heads. Ao, aorta; IVS, interventricular septum; $L A$, left atrium; $L V$, left ventricle; aml, anterior mitral leaflet; pml, posterior mitral leaflet. 


\section{Discussion}

This case report illustrates several points. First, with the increasing use of echocardiography, dissection of the interventricular septum, a very rare complication of sinus of Valsalva aneurysm which used to be a post-mortem finding, can be correctly diagnosed even
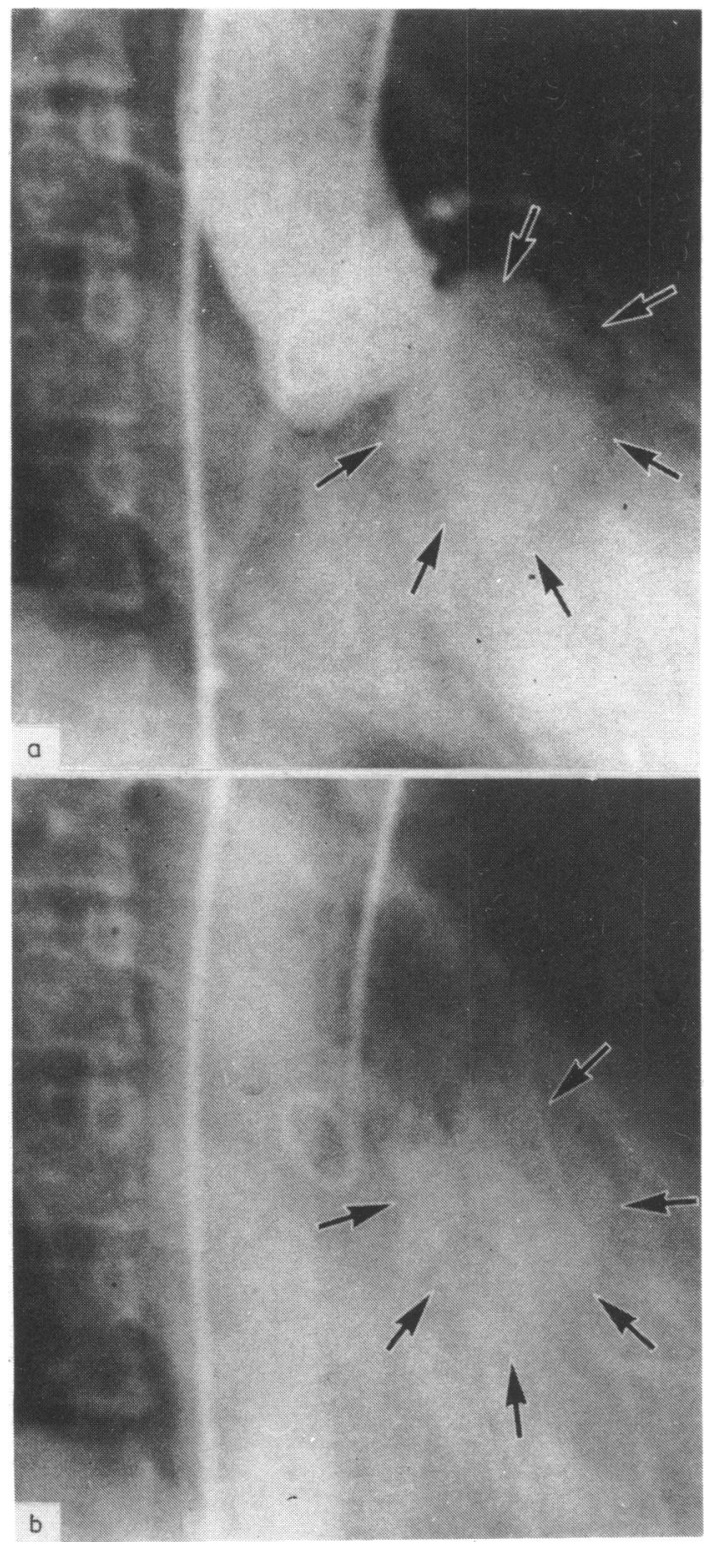

Fig. 3 Aortogram (30 degree RAO) with dye injected near the aortic valve. (a) Dissection into the interventricular septum as outlined by arrows. (b) Late film showing the persistence of dye within the dissection as outlined by arrows. before cardiac catheterisation. In our patient, an echo free space was present in the interventricular septum. Diastolic expansion of the echo free space in the interventricular septum demonstrated that it was in continuity with a high pressure chamber. In the present case, this could only have been the ascending aorta. This permits the differential diagnosis from a sonolucent myocardial infarction or possibly a cystic space.

A common feature reported in sinus of Valsalva aneurysm dissecting into the interventricular septum is the presence of atrioventricular conduction disturbances. Cases reported frequently showed either atrioventricular block or bundle-branch block. This case illustrates that sometimes, even in patients with large dissection of the interventricular septum, the atrioventricular node may be spared as shown by the absence of atrioventricular conduction disturbance in our patient.

The aetiology of the cardiovascular abnormalities in our patient is uncertain. It is tempting to suggest syphilitic aortitis as the case of the aortic regurgitation and the aneurysm of the sinus of Valsalva. Syphilis has been claimed to be an aetiological factor ${ }^{6}{ }^{7}$ though the great majority of cases are congenital. Unfortunately our patient refused surgery. In the absence of operative and pathological confirmation of syphilitic aortitis, the possibility of congenital aneurysm of sinus of Valsalva with aortic regurgitation cannot be excluded.

\section{References}

1 Warthen RO. Congenital aneurysm of the right anterior sinus of Valsalva (interventricular aneurysm) with spontaneous rupture into the left ventricle. Am Heart $\mathcal{F}$ 1949; 37: 975-81.

2 Lee EB, Krieger OJ, Lee NK. Congenital aneurysm of the noncoronary sinus of Valsalva leading to complete heart block: case report. Ann Intern Med 1956; 45: 525-34.

3 Gibbs NM, Harris EL. Aortic sinus aneurysms. Br Heart f 1961; 23: 131-9.

4 Onat A, Ersanli O, Kanuni A, Aykan TB. Congenital aortic sinus aneurysms, with particular reference to dissection of the interventricular septum. Am Heart f 1966; 72: 158-64.

5 Engel PJ, Held JS, van der Bel-Kahn J, Spitz H. Echocardiographic diagnosis of congenital sinus of Valsalva aneurysm with dissection of the interventricular septum. Circulation 1981; 63: 705-11.

6 Taussig HB. Congenital malformations of the heart. New York: Commonwealth Fund, 1947: 418-26.

7 Morgan Jones A, Langley FA. Aortic sinus aneurysms. Br Heart f 1949; 11: 325-41.

Requests for reprints to Dr Walter W C Chen, University Department of Medicine, Queen Mary Hospital, Hong Kong. 